\title{
A new therapeutic basis for treating Li-Fraumeni Syndrome breast tumors expressing mutated TP53
}

\section{Robert I. Glazer}

* Department of Oncology, Lombardi Comprehensive Cancer Center, Georgetown University School of Medicine, Washington, DC 20007, USA

Correspondence to: Robert I. Glazer, e-mail: glazerr@georgetown.edu

Commentary on: Herbert et al.. A molecular signature of normal breast epithelial and stromal cells from Li-Fraumeni syndrome mutation carriers. Oncotarget. 2010; 1:405.422

Received: September 15, 2010, Accepted: October 15, 2010, Published: October 17, 2010

Copyright: $\odot$ Glazer et al. This is an open-access article distributed under the terms of the Creative Commons Attribution License, which permits unrestricted use, distribution, and reproduction in any medium, provided the original author and source are credited.

Li-Fraumeni Syndrome (LFS) is a rare autosomal dominant disorder characterized by germline mutations in TP53 and the early onset of multiple forms of cancer, including breast cancer $[1,2]$. As predicted by the Knudsen two-hit hypothesis, mutation or inactivation of one allele results in somatic inactivation of the second allele, ie. loss of heterozygosity [3]; however, one-hit effects without $\mathrm{LOH}$ can also account for an increased growth advantage and tumorigenicity [4]. The National Comprehensive Cancer Network (NCCN) provides guideline recommendations for screening LFS family members to aid early detection of tumors. However, many LFS families remain undiagnosed as a result of a lack of atypical histopathological presentations that can be used to identify these families. Additionally, diagnosis is complicated by the fact that almost all LFS-associated
TP53 mutations are missense, which often make clinicians reluctant to make a diagnosis of LFS due to the inherent ambiguity of classifying missense variants. Therefore, better molecular diagnostics for LFS family members are needed so that they can benefit from screening. Because TP53 mutations are among the most common in all tumors, LFS diagnostics have great potential to be applied to early detection of sporadic tumors in patients whose tumors acquire somatic TP53 mutations. Herbert et al. now report differences in the molecular signature associated with two breast epithelial and stromal cell lines derived from LFS patients with different TP53 mutations. They assess differences between these two LFS genotypes and normal control tissue by gene array analysis, and compare the relative sensitivity of target genes to TP53modifying drugs.

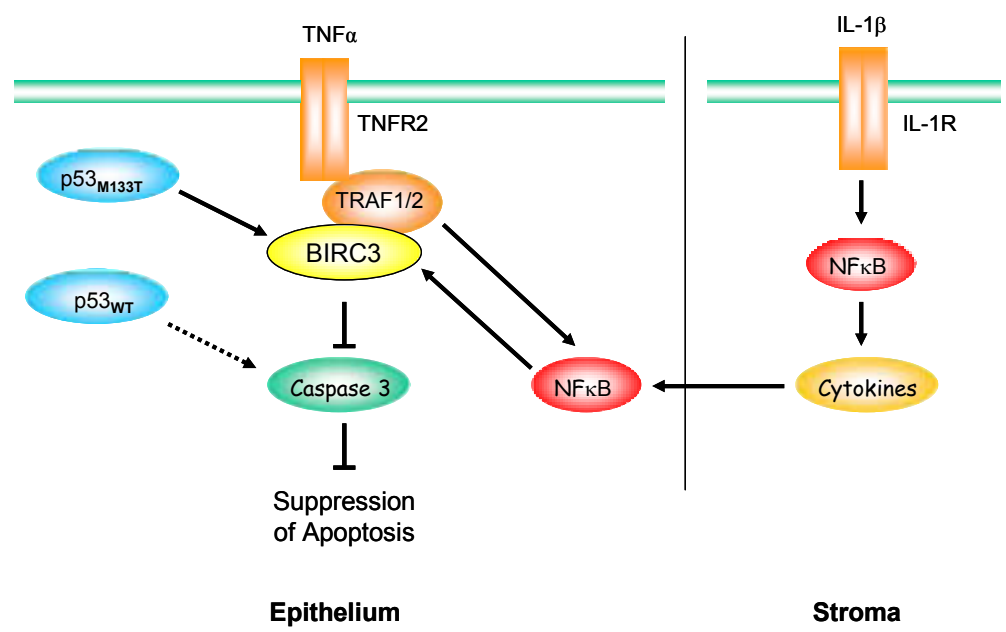

Figure 1: Survival pathways associated with the Li-Fraumeni mutated TP53 phenotype. Li-Fraumeni Syndrome (LFS) breast epithelial cells heterozygous for TP53 mutation M133T exhibit a marked upregulation of BIRC3 expression. BIRC3 associates with the TNF $\alpha$ receptor 2 (TNFR2)-associated proteins, TRAF1 and TRAF2, to inhibit caspase-3 activation and block apoptosis. Additionally, TRAF1/2 upregulates expression of transcription factor NFKB, which in turn increases BIRC3 expression.

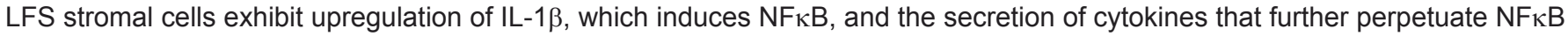
expression and pro-survival signaling. 
Herbert et al. demonstrate that breast epithelial cells with the TP53 M133T mutation (LFS-50) exhibit a marked increase (20-40-fold) in expression of the antiapoptotic gene, BIRC3, as well as an increase in IL- $1 \beta$ gene expression in stromal cells. This contrasts with little or no changes in the expression of these genes in epithelial and stromal cells (LFS-IUSM) derived from a patient with the frameshift mutation. This remarkable difference suggests that cells heterozygous for mutated TP53, in contrast to those expressing wild-type TP53, may have a survival advantage. BIRC3 associates with the TNFR2associated factor, TRAF2, which mediates inhibition of caspase-3 [5] (Fig. 1). TRAF2 also promotes increased NFkB expression, a transcription factor that upregulates BIRC3 expression [6]. Since stromal cells associated with the mutated TP53 phenotype exhibit elevated expression of IL-1 $\beta$, which also activates NFKB signaling and the expression of inflammatory cytokines, this suggests a scenario, whereby cytokine secretion by adjacent stromal cells can exacerbate the antiapoptotic signaling pathway in epithelial cells (Fig. 1). Interestingly, the high frequency of osteosarcomas in heterozygous TP53 mice [7], as in LFS patients [2], exhibit a similar increase in Birc3 gene expression, and a dependency on this gene for tumor growth.

Herbert et al. also provide a basis for a therapeutic approach that may selectively inhibit tumors in LFS patients expressing the mutated TP53 phenotype. Treatment of LPS-50 cells with both CP-31398 and PRIMA-1, drugs believed to interrupt signaling by mutated TP53 and convert the mutated TP53 conformation to the wild-type conformation [8,9], produced a synergistic inhibitory effect on BIRC3 expression, and a reduction in cell growth. These results imply that therapy targeting mutated TP53 may selectively induce apoptosis in tumors from patients with this genotype. These studies also suggest that patients with the inflammatory gene signature in stromal tissue may derive additional benefit from treatment with anti-inflammatory therapy to interrupt the feed forward pro-survival cycle induced by mutated TP53.

\section{REFERENCES}

1. Li, FP and Fraumeni, JF, Jr. Soft-tissue sarcomas, breast cancer, and other neoplasms. A familial syndrome? Ann Intern Med 1969; 71: 747-752.

2. Li, FP, Fraumeni, JF, Jr., Mulvihill, JJ, Blattner, WA, Dreyfus, MG, Tucker, MA and Miller, RW. A cancer family syndrome in twenty-four kindreds. Cancer Res 1988; 48: 5358-5362.

3. Knudson, AG, Jr. Mutation and cancer: statistical study of retinoblastoma. Proc Natl Acad Sci U S A 1971; 68: 820823.

4. Yeung, AT, Patel, BB, Li, XM, Seeholzer, SH, Coudry, RA, Cooper, HS, Bellacosa, A, Boman, BM, Zhang, T, Litwin,
S, Ross, EA, Conrad, P, Crowell, JA, Kopelovich, L and Knudson, A. One-hit effects in cancer: altered proteome of morphologically normal colon crypts in familial adenomatous polyposis. Cancer Res 2008; 68: 7579-7586.

5. Rothe, M, Pan, MG, Henzel, WJ, Ayres, TM and Goeddel, DV. The TNFR2-TRAF signaling complex contains two novel proteins related to baculoviral inhibitor of apoptosis proteins. Cell 1995; 83: 1243-1252.

6. Aizawa, S, Nakano, H, Ishida, T, Horie, R, Nagai, M, Ito, $\mathrm{K}$, Yagita, H, Okumura, K, Inoue, $\mathrm{J}$ and Watanabe, $\mathrm{T}$. Tumor necrosis factor receptor-associated factor (TRAF) 5 and TRAF2 are involved in CD30-mediated NFkappaB activation. J Biol Chem 1997; 272: 2042-2045.

7. Ma, O, Cai, WW, Zender, L, Dayaram, T, Shen, J, Herron, AJ, Lowe, SW, Man, TK, Lau, CC and Donehower, LA. MMP13, Birc2 (cIAP1), and Birc3 (cIAP2), amplified on chromosome 9, collaborate with p53 deficiency in mouse osteosarcoma progression. Cancer Res 2009; 69: 25592567.

8. Bykov, VJ, Issaeva, N, Selivanova, G and Wiman, KG. Mutant p53-dependent growth suppression distinguishes PRIMA-1 from known anticancer drugs: a statistical analysis of information in the National Cancer Institute database. Carcinogenesis 2002; 23: 2011-2018.

9. Rippin, TM, Bykov, VJ, Freund, SM, Selivanova, G, Wiman, KG and Fersht, AR. Characterization of the p53rescue drug CP-31398 in vitro and in living cells. Oncogene 2002; 21: 2119-2129. 